DOI: $10.30612 /$ re-ufgd.v4i8.6801

\title{
ENSINO DA LÍNGUA PORTUGUESA PARA ALUNOS SURDOS POR MEIO DE JOGO: UMA AÇÃO DO PIBID LETRAS/LIBRAS/EAD/UFGD
}

Teaching of The Portuguese Language for deaf students by means of game: an action of PIBID Letras/Libras/Ead/UFGD

Jakellinny Gonçalves de Souza Rizzo ${ }^{1}$ Karla Alexandra Benites Florenciano ${ }^{2}$

Rutnéia de Ávila Pereira ${ }^{3}$

Recebido em 28/08/2017 Aceito em 15/12/2017

Resumo: Objetiva-se com este trabalho apresentar a criação e a aplicabilidade de um jogo que auxilie no ensino aprendizagem da Língua Portuguesa (LP) para estudantes surdos. Do qual, foi elaborado por acadêmicas do curso de licenciatura em Letras LIBRAS da Faculdade de Educação a Distância - EaD da Universidade Federal da Grande Dourados (UFGD), apoiadas pelo Programa Institucional de Bolsas de Iniciação à Docência (PIBID) que desenvolve o subprojeto Letras LIBRAS em uma escola da rede pública estadual, no município de Dourados, Mato Grosso do Sul. Inicialmente serão apresentadas as atividades desenvolvidas, em seguida os métodos e na sequência os resultados. Percebe-se, que a utilização de jogos midiáticos é uma ferramenta significativa e que contribui positivamente no processo de ensino aprendizagem de LP para estudantes surdos.

Palavras-chave: Estudantes. Aprendizagem. Português.

Abstract: The objective of this work is to present the creation and applicability of a game that helps in the teaching of the Portuguese Language (LP) for deaf students. Of which, it was elaborated by academics of the licentiate course in Libras Letters of the Faculty of Distance Education - EaD of the Federal University of Grande Dourados (UFGD), supported by the Institutional Program of Initiatives for Teaching (PIBID) that develops the subproject Letters Pounds at a state public school in the city of Dourados, Mato Grosso do Sul. Initially, the activities developed will be presented, followed by the methods and in sequence the results. It is noticed that the use of media games is a significant tool and contributes positively in the teaching process of LP learning for deaf students.

Keywords: Student. Learning. Portuguese.

\section{Introdução}

O principal objetivo deste trabalho é apresentar o desenvolvimento de um jogo midiático elaborado para auxiliar estudantes surdos na aquisição da Língua Portuguesa (LP) na modalidade escrita como segunda

\footnotetext{
${ }^{1}$ Mestranda em Educação - UFGD - E-mail: jake.librasufgd@gmail.com

${ }^{2}$ Graduada em Pedagogia, pós-graduada em Psicopedagogia, acadêmica do curso de Letras/Libras - UFGD. Professora do curso de Pedagogia - UFMS/CPPP - E-mail: karlinhaben@gmail.com

${ }^{3}$ Graduada em Letras/Inglês - UFGD; Especialista em Estudos Linguísticos UEMS - Discente de Letras Libras -

- UFGD - E-mail: rutinha.avila@gmail.com
} 
língua (L2), pois tais estudantes possuem como língua materna, a Língua Brasileira de Sinais (LIBRAS).

A motivação inicial para a elaboração do jogo, partiu de ideias e questionamentos de acadêmicas do curso de licenciatura em Letras Libras da Faculdade de Educação a Distância EaD - Universidade Federal da Grande Dourados (UFGD) no decorrer do Programa Institucional de Bolsas de Iniciação à Docência (PIBID) que vincula às Instituições de Ensino Superior (IES) as escolas da rede pública.

Assim, o subprojeto de Letras LIBRAS está vinculado a uma escola pública da rede estadual da cidade de Dourados - MS, e proporciona aos estudantes de licenciatura o desenvolvimento de atividades para contribuírem no processo de ensino e aprendizagem na área da educação de surdos, elaborando práticas pedagógicas que atendam as especificidades educacionais desses alunos.

O ensino da LP tem sido um grande desafio para os educadores de alunos surdos. Durante muito tempo predominou na educação dos surdos o oralismo, ou seja, ensino e aprendizagem da LP na modalidade oral.

Com a oficialização da LIBRAS, pela Lei Federal 10.4366/2002 e com aprovação do Decreto Federal no 5.626, de 22 de dezembro de 2005, os surdos passaram a serem reconhecidos politicamente em todo Brasil como um grupo que possui uma cultura própria e uma língua própria, a lei e o decreto estabeleceram a obrigatoriedade das escolas possibilitarem aos alunos surdos uma educação bilíngue, na qual a LIBRAS é a primeira língua (L1) e a Língua Portuguesa (LP) é a segunda língua (L2) na modalidade escrita, dessa forma, a LIBRAS foi inserida no contexto da educação dos surdos.

É importante ressaltar que atualmente a abordagem metodológica que norteia a educação dos surdos no mundo é o bilinguismo, do qual, a criança surda primeiramente adquire sua língua materna, ou seja, LIBRAS e posteriormente, a língua escrita do seu país.

O bilinguismo é uma proposta de ensino usada por escolas que se propõe a tornar acessível à criança as duas línguas no contexto escolar. Os estudos têm apontado para essa proposta como sendo mais adequada para o ensino de crianças surdas, tendo em vista que considera a língua de sinais como língua natural e parte desse pressuposto para o ensino da língua escrita. (QUADROS, 1997 p.27).

Esta abordagem tem sido muito discutida na área da surdez devido à inclusão dos alunos surdos nas escolas regulares, é uma proposta de ensino que propõe que as escolas ofereçam acessibilidade aos alunos surdos, oportunizando as duas línguas no processo educacional.

Sendo assim, diante desse desafio do ensino-aprendizagem da LP na modalidade escrita como L2 para alunos surdos é necessário elaborar e pensar em estratégias para que o ensino seja proveitoso. Dessa forma, para nortear a confecção dos materiais pedagógicos como jogos entre outros, é relevante entender a cultura e a identidade surda, para isso foram realizadas leituras de autores/pesquisadores conceituados na área de LIBRAS, como Quadros (1997); Strobel (2008); Lacerda (1998); Skiliar (2011), os quais compuseram a fundamentação teórica para o desenvolvimento dos materiais.

O desenvolvimento da ação originou-se de discussões e planejamento coletivos nas reuniões do PIBID, onde objetivou trabalhar com material adaptado para desenvolver o 
aprendizado da L2 na modalidade escrita através do jogo educativo, qual conta com uma abordagem de ensino diferenciada, espera-se que com a utilização do jogo os alunos surdos aprendam de maneira mais dinâmica e lúdica as características da L2 na modalidade escrita.

\section{Metodologia}

O jogo foi elaborado nos encontros dos pibidianos que ocorreram numa escola estadual do município de Dourados/MS na Sala de Recurso Multifuncional (SRM) om Atendimento Educacional Especializado (AEE) na área da surdez. A ideia da criação do jogo utilizando recursos tecnológicos foi elaborada estrategicamente considerando as características do grupo de alunos surdos a ser aplicado o jogo, seriam alunos do ensino médio com faixa etária de 14 a 19 anos, a facilidade de acesso e manuseio das ferramentas tecnológicas (computadores e celulares).

Inicialmente o grupo de pibidianos selecionaram os verbos a serem trabalhados no jogo e seus respectivos sinais. Utilizandose de máquina fotográfica, foram realizadas as sessões de fotos e, posteriormente, a edição de todo material, no espaço da SRM. Pode-se observar na imagem (1) abaixo:

Figura 1. Desenvolvimento do Jogo dos Verbos

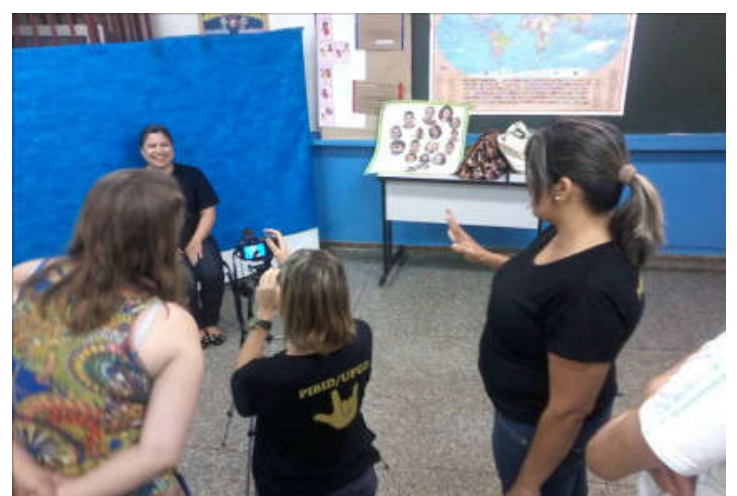

O jogo funciona da seguinte maneira: ao aparecer o sinal do verbo em LIBRAS o aluno tem que selecionar o verbo correspondente na LP que melhor se encaixa na oração proposta,

\section{Assimilação do Item Lexical no Português}

- Tiveram Dificuldades em Assimilar o Item Lexical Assimilaram mas não dominaram o Item Lexical $\square$ Dominaram o Item Lexical

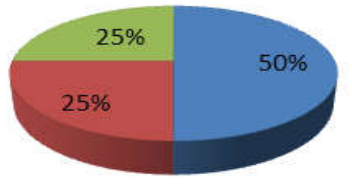

e dessa forma, o sistema vai mostrar se a opção escolhida está correta ou errada, após acertar uma pergunta o aluno passará para a próxima pergunta automaticamente. Observe na figura (2) a seguir:

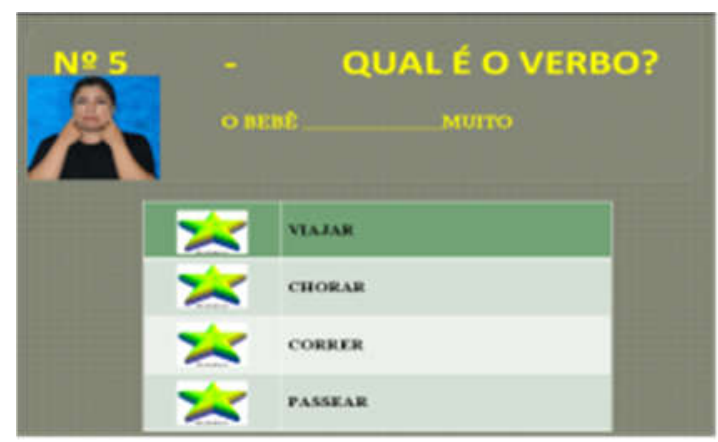

Figura 2. Layout do Jogo dos Verbos

Ao encerrar a confecção do jogo, foi oferecida pelos acadêmicos uma oficina na SRM para os alunos surdos do ensino médio. Realizadas as explicações sobre as regras do jogo, foi destinado um computador para cada aluno, com o objetivo de aprender os verbos na modalidade escrita da LP. Conforme a figura (3) abaixo: 


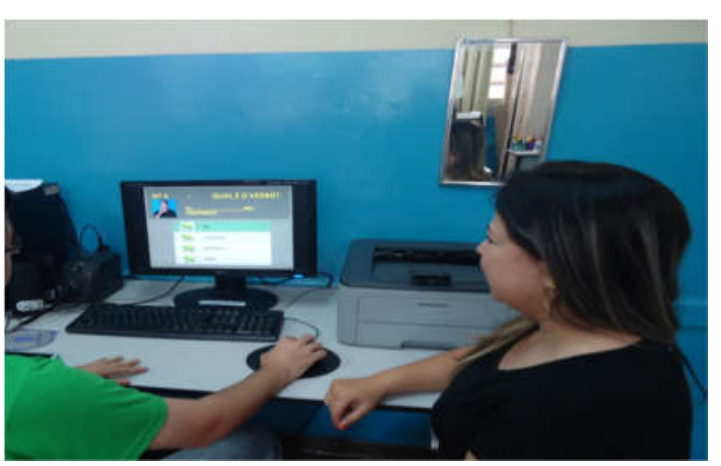

Figura 3. Aplicação do Jogo dos Verbos

Ao final da aplicação do jogo, os alunos surdos participantes juntamente como os pibidianos fizeram uma análise da experiência.

\section{Resultados e Discussões}

Observamos a participação dos alunos que demonstraram interesse na atividade oferecida pelos pibidianos. Notou-se entre os alunos algumas iniciativas de ajudar o colega a compreender as regras do jogo, apontando $o$ interesse destes.

Considerando a assimilação do item léxico no português, obtivemos os seguintes dados:

O jogo proporcionou momentos de interação entre os alunos e principalmente o aumento do vocabulário da LP na modalidade escrita, as orações em letras maiúsculas no layout do jogo referia a transcrição da Língua Brasileira de Sinais (LIBRAS) com os verbos na forma infinitiva na respectiva ordem: Sujeito-Verbo-Objeto.

Os alunos surdos referiram gostar da aula ministrada utilizando o jogo, pois usaram o computador como ferramenta de ensino-aprendizagem, o que é diferente da rotina que estavam acostumados, com isso puderam aprender de forma mais dinâmica, saindo do cotidiano da SRM.

Os alunos surdos contribuíram com algumas sugestões para que o jogo pudesse promover ainda mais no aprendizado, como por exemplo, imagens que contextualizem os verbos, vídeos explicativos em LIBRAS, com exemplos dos verbos e uma versão para as crianças para alfabetização da LP na modalidade escrita.

As sugestões dadas pelos alunos surdos foram analisadas pelo grupo de pibidianos para que pudesse ser elaborada a próxima versão do jogo com verbos. Esse momento com os alunos foi satisfatório, tendo em vista a possibilidade de refletirmos sobre um novo material didático voltado para todas as idades, sendo o conteúdo voltado para o processo de ensino-aprendizagem da LP, como L2, já que os resultados foram positivos. Durante todo o desenvolvimento desde o início dos planejamentos, da elaboração e da aplicação, pudemos perceber que a utilização de jogos midiáticos influencia de maneira positiva o processo de ensino e aprendizagem.

Observou que durante aulas que utilizaram os jogos houve uma interação maior entre professor e alunos, inclusive entre os próprios alunos ocorreram mais diálogos, enquanto tentavam ajudar um ao outro, demonstrando envolvimento com o jogo.

O jogo dos verbos buscou uma forma de estreitar o contato dos alunos com ensino da LP na modalidade escrita, proporcionando através da diversão a aprendizagem da LP sem que fosse exaustivo.

Com os resultados notou-se que o jogo midiático proporciona uma aprendizagem recíproca e recreativa socializando os alunos surdos no ambiente escolar. Destacamos, por fim, que esses pressupostos metodológicos e organizacionais do jogo possibilitam um sistema educacional bilíngue, numa perspectiva que alcance novas práticas 
pedagógicas a qual valorizem as diferenças

linguísticas da comunidade surda.

\section{Referências}

BRASIL. Lei $\mathbf{n}^{\mathbf{1}} \mathbf{1 0 . 4 3 6}$, de $\mathbf{2 4}$ de Abril de 2002. Disponível em: http://www.planalto.gov.br/ccivil_03/leis/2002/110436.htm. Acessado em 29 de abril de 2016.

Decreto $n^{0}$ 5.626, de 22 de dezembro de 2005. Regulamenta a Lei $n^{0} 10.436$, de 24 de abril de 2002. Disponível em: http://www.planalto.gov.br/ccivil_03/_ato20042006/2005/decreto/d5626.htm. Acessado em 29 de abril de 2016.

QUADROS, R. Educação de surdos: Aquisição da linguagem. Porto Alegre: Artmed, 1997.

LACERDA, C. B.F. de. Um pouco da história das diferentes abordagens na educação dos surdos. Cad. CEDES v.19 n.46 Campinas Sept. 1998

STROBEL, K. - As Imagens do outro sobre a Cultura Surda. Editora UFSC: Florianópolis, 2008.

SKLIAR, C. (org.) A Surdez: um olhar sobre as diferenças. $5^{\circ}$ ed. Porto Alegre: Mediação, 2011. 